\title{
New Approaches for Reducing the Cost of the Synthetic Seeds Storage Using Sugarcane Bagasse and Different Additives to the Gel Matrix for Sugarcane Plant: In vitro
}

\author{
Awatef Mahmoud Badr-Elden \\ Plant Biotechnology Department, Genetic Engineering and Biotechnology Research \\ Institute (GEBRI), University of Sadat City, Sadat City, Egypt.
}

\begin{abstract}
SUGARCANE (Saccharum officinarum L.) is a perennial monocot plant, the major source of sugar and an important cash crop in the world. The plant does not produce seeds in Egypt and mostly produced through vegetative propagation. Hence, it is necessary to propagate this plant through in vitro culture for large scale production, which can be used commercially for germplasm conservation using synthetic seeds. New supporting material like sugarcane bagasse reducing the cost of synthetic seeds storage and different additive to the gel matrix were used. In vitro production and conservation of synthetic seed in sugarcane plant were studied. Encapsulation is a method for micro- shoots coating using Na-alginate for synthetic seeds conservation. The developed protocol in this study is a simple and effective tool for mass propagation, storage of synthetic seeds and minimize the production cost as well. Maximum shoots proliferation was observed on MS medium containing $1 \mathrm{mg} / 1 \mathrm{BA}$ and $0.8 \mathrm{mg} / \mathrm{l} \mathrm{NAA}$. Sodium alginate was very effective for the formation of uniform and firm capsules at the concentration $4 \%(\mathrm{w} / \mathrm{v})$ sodium alginate and $100 \mathrm{mM}$ calcium chloride. The highest germination rate of synthetic seeds was recorded at 20 or $25 \mathrm{~g} / 1$ sucrose in the gel matrix. The synthetic seeds with synthetic endosperm consist of MS medium supplemented with, ABA at (1.00 or 1.25 $\mathrm{mg} / \mathrm{l})$ gave the lowest regrowth of synthetic seeds $(1.66 \%)$ with high viability and the ability to regrowth when they transferred to the natural environmental conditions. Maximum regrowth and low storage cost of synthetic seeds were obtained with MS medium supplemented with sugarcane bagasse compared with those grown on agar-gelled media.
\end{abstract}

Keywords: Artificial seeds, In vitro, Sugarcane, Sugarcane bagasse.

\section{Introduction}

Sugarcane (Saccharum officinarum) is a monocotyledonous perennial grass that is cultivated in the tropical and subtropical regions of the world, primarily for its ability to accumulate high concentration of sucrose in its stem. Sugarcane is recommended for sound and healthy body. Stems and roots of sugarcane are used in Ayurvedic medicine to treat urinary tract infections and skin, as well as for bronchitis, loss of milk production, heart conditions, anemia, cough, constipation as well as general debility. Some recommended its use for jaundice and low blood pressure (Kadam et al., 2008). Commercial sugarcane hybrid cultivars have arisen through intensive selective breeding of species within the Saccharum genus, primarily involving crosses between Saccharum. officinarum and Saccharum officinarum spontaneum. Saccharum officinarum highly susceptible to diseases and accumulates sucrose at high levels in the stem (Lakshmanan et al., 2006 and Cox et al., 2000). On the other hands, whereas Saccharum spontaneum accumulates less sucrose, exhibits higher fiber content with thinner stalks but it is a highly polymorphic species with tolerance to the diseases and many pests (Jackson, 2005). To solve the problems of traditional propagation utilizes the industry of sugar in vitro propagation technique, which is described by rapid multiplication to obtain free disease for sugarcane (Soodi et al., 2006). Micropropagation is an important technique to generate a large number of shoots in a short time (Hailu, 2017). In vitro of sugarcane shoot propagation $(87.58 \%)$ occurred on MS medium supplemented with NAA (5.0 $\mathrm{mg} / \mathrm{L}$ ) and Kinetin $(0.5 \mathrm{mg} / \mathrm{L})$ (Kaur \& Kapoor, 2017). The encapsulation technique is designed to combine the advantages of clonal propagation with those of seeds propagation and storage (Ara et al., 2000). Advantages of synthetic seeds include 
their designation as easily handling, 'genetically identical', easy transportation, saving time, labor space and minimize the overall cost (Nyende et al., 2003). Encapsulation is an effective approach for in vitro propagation of plant species that given with a high number of non-viable seeds (Daud, 2008). The artificial seeds can be used for multiplication of several commercially an important like sugarcane as agronomic crops (currently propagated by cuttings) (Helal, 2011). Sodium alginate (2.5\%) and $\mathrm{CaCl}_{2} \cdot 2 \mathrm{H}_{2} \mathrm{O}(100 \mathrm{mM})$ solutions were found to be the optimal concentration for producing firm, transparent and uniform synthetic seeds (Soni \& Sharma, 2017).

Biotechnological application was using for rooting of apple rootstocks in micropropagation technology sugarcane bagasse as a support material (Mohan et al., 2004). Mechanical supports of sugarcane bagasse are used in safe, it is an autoclavable, not toxic compounds, not be digested by the plant enzymes and not react with the media contents (Mohan et al., 2005). The aim of this research was to investigate the optimum concentration of sodium alginate and calcium chloride that is required for encapsulation of microshoots of sugarcane. Another objective was to evaluate the effect of alginate matrix components, the presence MS nutrient salts contained different concentrations of sucrose or ABA on storage of synthetic seeds and storage of synthetic seeds at low temperature $\left(4,10\right.$ or $\left.15^{\circ} \mathrm{C}\right)$. In addition, evaluate three different supporting materials in MS medium, i.e. (sugarcane bagasse, perlite and agar) in order to determine the low cost among them.

\section{Materials and Methods}

\section{Explant preparation and sterilization}

Healthy young meristems were collected by removing the leaf sheath from field grown plants of sugarcane (Saccharum officinarum L.) maintained in the Farm of Genetic Engineering and Biotechnology Research Institute, University of Sadat City, Egypt. Explants were surface sterilized $\left(0.1 \% \mathrm{HgCl}_{2}\right.$ for $\left.10 \mathrm{~min}\right)$ (Kaur \& Kapoor, 2017). A nodal portion of spindle was discarded and the outer two or three whorls of leaves were removed using a sharp scalpel blade. Innermost leaf whorls were cut obliquely $(0.5-1.0 \mathrm{~cm})$ in order to achieve callus initiation and were used as an explant for culturing. Explant cultures were established by culturing the nodal portion of spindle segments on Murashige \& Skoog (1962) MS medium supplemented with $1 \mathrm{mg} / \mathrm{l}$ benzyl adenine (BA). The cultures were incubated at $25 \pm 2^{\circ} \mathrm{C}$ and low light for first 15 days before shifting to illumination of 2000 lux white fluorescent light, with $16 / 8 \mathrm{~h}$ (light/dark) photoperiod regimes. Regenerated plants from nodal were sub-cultured for further multiplication at fortnight intervals.

\section{Multiplication of shoots \\ Regeneration of micro- shoots}

Shoots were cultured on full MS medium supplemented with $1 \mathrm{mg} / \mathrm{L}$ BA and different combinations and concentrations of IBA and NAA (0.1-0.8mg/L) for multiple shoot regeneration either individually or in combination. The culture was maintained in a growth chamber at $25 \pm 2^{\circ} \mathrm{C}$ provided by cool-white fluorescent light (2000 lux) for $16 \mathrm{~h}$ photoperiod. Two months After proliferation stage, number of shoot length $(\mathrm{cm})$ and a number of shoots were recorded.

\section{Synthetic seeds production}

Effect of different concentrations of sodium alginate and calcium chloride on germination of synthetic seeds

After several subcultures, micro- shoots, were randomly chosen at the end of the third subculture period and they were used for encapsulation of micro shoots. Micro-shoots $(0.5 \mathrm{~cm}$ long) were isolated and mixed with different solutions of autoclaved Na-alginate at 2, 3 or $4 \%(\mathrm{w} / \mathrm{v})$ prepared in MS medium then they were dropped into the complexing solution of calcium chloride $\left(\mathrm{CaCl}_{2} \cdot 2 \mathrm{H}_{2} \mathrm{O}\right)$ at 25 , $50,75,100$ or $125 \mathrm{mM}$ for 30 min using a sterile pipette of appropriate diameter on a gyratory shaker (80 rpm). Each drop contained one micro- shoots. After the incubation period, the synthetic seeds were recovered by decanting the $\mathrm{CaCl}_{2} \cdot 2 \mathrm{H}_{2} \mathrm{O}$ solution and washing them several times with autoclaved distilled water. After encapsulation, the beads were cultured in jars $(250 \mathrm{ml})$ containing MS basal medium supplemented with $30 \mathrm{~g} / \mathrm{L}$ sucrose, $0.25 \mathrm{mg} / \mathrm{L} \mathrm{BA}$ and $7 \mathrm{~g} / \mathrm{L}$ agar then they were stored at $20^{\circ} \mathrm{C}$ (in darkness) for four weeks. Germination $\%$ of synthetic seeds was recorded after four weeks

Slow growth and preservation of synthetic seeds Effect of addition of sucrose in gel matrix and conservation period (week) on germination of synthetic seeds

In this experiment, the effect of sucrose that was added in the gel matrix of capsules at different concentrations $5,10,15,20,25$ or $30 \mathrm{~g} / \mathrm{L}$ and storage at different periods, 2, 4, 6 and 8 weeks were studied. Capsules were cultured on conversion medium consists of full-strength of MS basal nutrient medium supplemented with $0.25 \mathrm{mg} / \mathrm{L}$, 
$\mathrm{BA}, 30 \mathrm{~g} / \mathrm{L}$ sucrose and $6 \mathrm{~g} / \mathrm{L}$ agar. The capsules were incubated at $20^{\circ} \mathrm{C}$ day and night temperature under dark conditions. Data were recorded after 2, 4, 6 and 8 weeks as germination \% of capsules.

Effect of addition of $A B A$ in the gel matrix and conservation period (week) on germination of synthetic seeds

Single micro-shoots coated with $4 \%(\mathrm{w} / \mathrm{v})$ sodium alginate dissolved in distilled water were dropped onto $50 \mathrm{ml}$ of a $100 \mathrm{mM} \mathrm{CaCl} 2 \cdot 2 \mathrm{H}_{2} \mathrm{O}$ and dissolved in distilled water solution stirring for $30 \mathrm{~min}$. Then retrieved from solution and rinsed with sterilized distilled water. Formed capsules were cultured onto storage media consists of MS basal nutrient media supplemented with different concentration of ABA at 0.0, 0.2, 0.4, $0.6,0.8,1.0 \mathrm{mg} / \mathrm{L}, 30 \mathrm{~g} / \mathrm{L}$ sucrose and $6 \mathrm{~g} / \mathrm{L}$ agar. Encapsulated micro-shoots were incubated at $10^{\circ} \mathrm{C}$ day temperature and kept under dark conditions. Germination \% of encapsulated micro-shoots was recorded after 2, 4, 6, 8, 10 and 12 weeks.

Effect of different temperature and conservation period (week) on germination of synthetic seeds

Single micro-shoot was coated with $4 \%(\mathrm{w} / \mathrm{v})$ sodium alginate dissolved in distilled water and dropped onto $50 \mathrm{ml}$ of $100 \mathrm{mM} \mathrm{CaCl} \cdot 2 \mathrm{H}_{2} \mathrm{O}$ dissolved in distilled water solution and stirring for $30 \mathrm{~min}$. Then, they were retrieved from solution and rinsed with sterilized distilled water. Formed capsules were cultured onto conversion media consisting of MS basal nutrient medium, supplemented with $0.25 \mathrm{mg} / \mathrm{L} \mathrm{BA}, 30 \mathrm{~g} / \mathrm{L}$ sucrose and $6 \mathrm{~g} / \mathrm{L}$ agar. Encapsulated micro-shoots were cultured and incubated at 4,10 , and $20^{\circ} \mathrm{C}$ in the dark. Germination \% of synthetic seeds was recorded after 2, 4, 6, 8,10 and 12 weeks' intervals.

Using sugarcane bagasse and perlite for lowcost storage of synthetic seeds

Preparation of the sugarcane bagasse: Sugarcane bagasse was obtained from local sugarcane juice sellers in Egypt. Only the internal part (medullar parenchyma) of the bagasse was used. It was washed twice with tap water, and once with deionized water to remove soluble material including sugars and other impurities then dried at $90^{\circ} \mathrm{C}$ for $24 \mathrm{~h}$ in an air oven. The dried bagasse was cut into small pieces about 1-1.25 $\mathrm{mm}$ by stainless steel shears. Bagasse was sterilized at $121^{\circ} \mathrm{C}$, under a pressure of $1.1 \mathrm{~kg} / \mathrm{cm}^{2}$ for $20 \mathrm{~min}$. Encapsulated micro-shoots were cultured in jars $(250 \mathrm{ml})$ and each jar contained $35 \mathrm{ml}$ of full MS medium and subjected to three different treatments as follow: 1- Control treatment (cont.) were cultured on MS medium supplemented with $0.25 \mathrm{mg} / \mathrm{L} \mathrm{BA}, 30 \mathrm{~g} / \mathrm{L}$ sucrose and $7 \mathrm{~g} / \mathrm{L}$. 2- Encapsulation were cultured on MS medium supplemented with $0.25 \mathrm{mg} / \mathrm{L} \mathrm{BA}$, $30 \mathrm{~g} / \mathrm{L}$ sucrose and $2 \mathrm{~g} / \mathrm{L}$ perlite. 3- Encapsulation were cultured on MS medium supplemented with $0.25 \mathrm{mg} / \mathrm{L} \mathrm{BA}, 30 \mathrm{~g} / \mathrm{L}$ sucrose and $3 \mathrm{~g}$ of sugarcane bagasse.

\section{Statistical analysis}

All experiments were arranged in the factorial randomized design. Each treatment was represented as ten replicates, each replicate consisted of three explants. Data were subjected to analysis of variance (ANOVA). Significant differences among the various treatments were compared using LSD test at 5\% (Snedecor \& Cochran, 1989).

\section{Results and Discussion}

Proliferation of micro-shoots

Different concentrations of auxins (NAA, IBA) and benzyl adenine at (1 $\mathrm{mg} / \mathrm{L} \mathrm{BA})$ were used for shoot regeneration. During this study, shoot formation was highly affected by both type and concentrations of the growth regulators that were used in this investigation. Among different concentrations and combinations used for shoots proliferation and length of shoots, the best results were obtained when explants were cultured on MS medium containing BA at $1.0 \mathrm{mg} / \mathrm{L}$ and IBA at 0.8 $\mathrm{mg} / \mathrm{L}$ compared with other treatments as shown in Fig.1 and Fig. 8A. Shoots tips explants produced adventitious shoots according to the concentration of BA alone or in combination with NAA or IBA that were used. It was obvious from the result that, BA alone has low effect on in vitro propagation of sugarcane so that, the combination of BA and IBA or NAA is necessary for in vitro shoots formation. Best shoots multiplication and elongation of sugarcane were obtained on MS Medium supplemented with $1.0 \mathrm{mg} / \mathrm{LBA}+0.5 \mathrm{mg} / \mathrm{L}$ NAA (Tarique et al., 2010). Formation of adventitious shoots was stimulated by low auxin level in combination with high level of cytokinin in sugarcane (Belay et al., 2014). The greatest number of shoots $10.5 \pm 1.31$ with average shoot length $4.0 \pm 0.61 \mathrm{~cm}$ was obtained on MS medium supplemented with BA at $2.0 \mathrm{mg} / \mathrm{L})+$ IBA $(1.0 \mathrm{mg} / \mathrm{L})$ number of shoots $10.5 \pm 1.31$ with average shoot length $4.0 \pm 0.61 \mathrm{~cm}$ (Kaur \& Kapoor, 2017). Best shoots multiplication and elongation of sugarcane were obtained on MS Medium supplemented with $1.0 \mathrm{mg} / \mathrm{L} \mathrm{BA}+0.5 \mathrm{mg} / \mathrm{L}$ NAA. The greatest number of shoots $10.5 \pm 1.31$ with average shoot length $4.0 \pm 0.61 \mathrm{~cm}$ was obtained on MS medium supplemented with BA at $2.0 \mathrm{mg} / \mathrm{L}+$ IBA (1.0 mg/L) (Kaur \& Kapoor, 2017). 


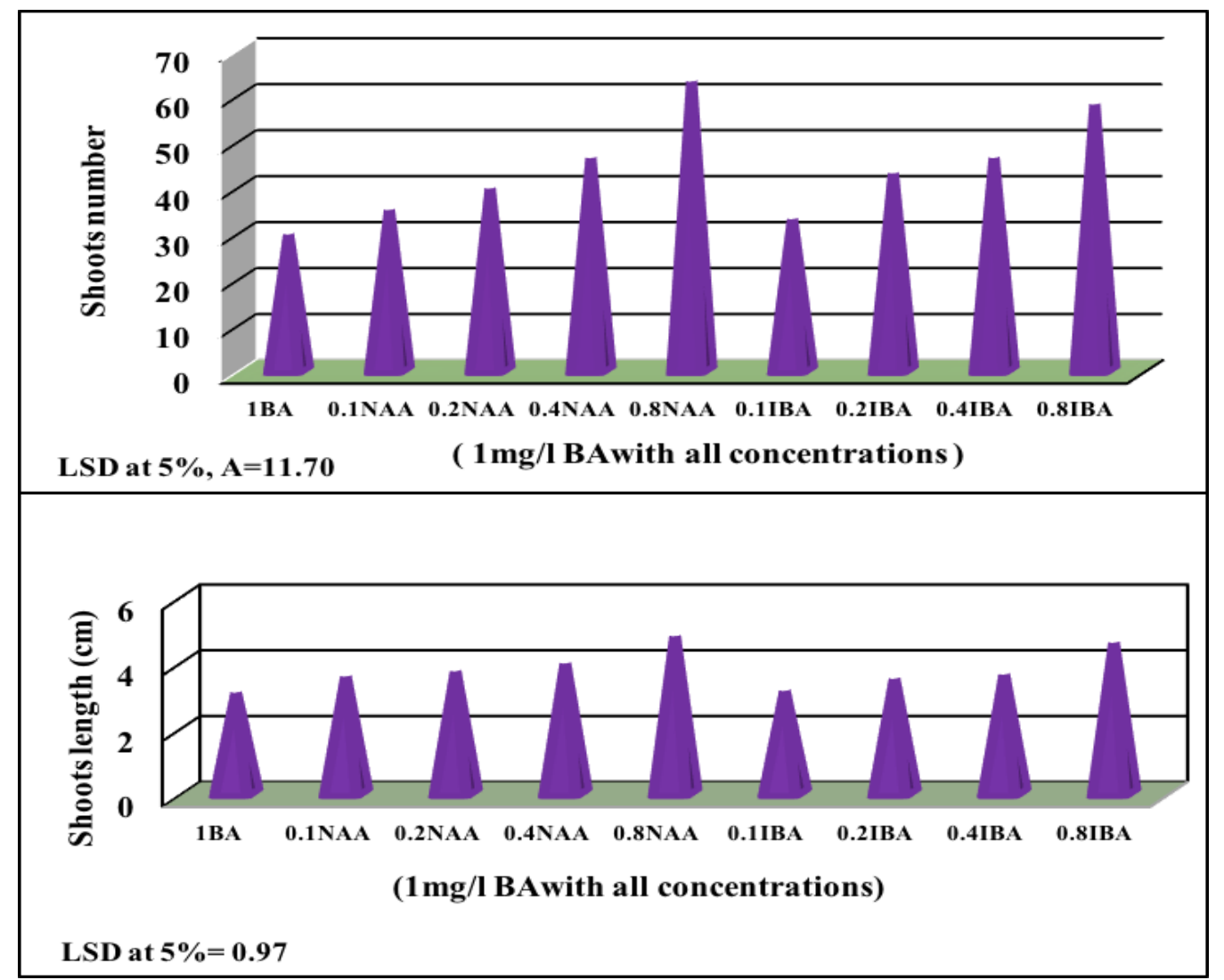

Fig. 1. Effect of different concentrations of auxins (NAA or IBA) and $1 \mathrm{mg} / \mathrm{L}$ BA on number and length of sugarcane shoots after two months of subcultures.

Effect of different concentrations of sodium alginate and calcium chloride on germination of synthetic seeds \%

Sodium alginate at 2, 3 or $4 \%$ was used as gel matrix for encapsulation of sugarcane formed in vitro. The results showed that sodium alginate at low concentration ( $2 \%)$, provided weak synthetic seeds and fragile to be handled. However, at higher levels (4\%) of sodium alginate, synthetic seeds were so hard that they easily cause considerable delay in conversion into the shoots. Optimal concentrations are 3 or $4 \%$ sodium alginate and 100 $\mathrm{mM} \mathrm{CaCl} 2.2 \mathrm{H}_{2} \mathrm{O}$ solution gave uniform, firm and identical capsules (Fig. 8C). Regarding the effect of interaction between different concentrations of sodium alginate and $\mathrm{CaCl}_{2} \cdot 2 \mathrm{H}_{2} \mathrm{O}$. Sodium alginate solution at $4 \%$ upon complexation with $100 \mathrm{mM}$ $\mathrm{CaCl}_{2} \cdot 2 \mathrm{H}_{2} \mathrm{O}$ solution gave the optimal significant percentage for storage of synthetic seeds (40\%) compared with other treatments as shown in Fig. 2. This data was supported by previous studies using different sodium alginate levels for capsulation of cucumber (Tabassum et al., 2010), on Acacia (Nor Asmah et al., 2012 and Badr-Elden, 2013) on strawberry. Development of the isodiametric compact bead of Stevia rebaudiana was formed by using $100 \mathrm{mM} \mathrm{CaCl}$, after15 min (Ali et al., 2012).

Slow growth preservation of synthetic seeds

Effect of sucrose in gel matrix on germination of synthetic seeds

The development of synthetic seeds was simultaneous and resulted in rapid regrowth of synthetic seeds within eight weeks. The presence of sucrose in gel matrix at 25 or $30 \mathrm{~g} / \mathrm{L}$ enhanced early development of shoot formation from synthetic seeds and gave 50 or $55.55 \%$ regrowth of synthetic seeds, respectively (Fig. 3). Increasing the storage time from one week to eight weeks increased germination \% of synthetic seeds from 0.00 to $72.00 \%$. Maximal regrowth was obtained at eight weeks and 25 or $30 \mathrm{~g} / \mathrm{L}$ sucrose in a gel matrix. From the obtained results, it found that presence of sucrose in the alginate gel matrix improved germination \% of synthetic seeds (Fig. $8 \mathrm{D})$. This result was in agreements with Rai et al. (2008) they found that a medium without sucrose caused complete inhibition of shoot 
regrowth from encapsulated shoot tips of Psidium guajava. Grzegorczyk et al. (2011) showed that regeneration of shoot and root from encapsulated shoot tips of Salvia officinalis L. after 6 weeks from germination of synthetic seeds when gel matrix contained 2\% sodium alginate, GA3 $(0.5$ or $1 \mathrm{mg} / \mathrm{L})$ and sucrose $15 \mathrm{~g} / \mathrm{L}$. Badr-Elden (2013) showed that encapsulated buds of Achemia fasciata lost the high amount of moisture and gives the lowest germination rate $(30.63 \%)$ when add $60.0 \mathrm{~g} / \mathrm{L}$ sucrose in the alginate matrix and storage for eight weeks. Increased in conversion of capsules of sugar beet and shoots turned green, produced at low concentration $(30 \mathrm{~g} / \mathrm{L})$ of sucrose (Rizkalla et al., 2012). Addition of 3\% sucrose in the gel matrix of synthetic seeds of Glochidion velutinum plays an important role in the regrowth of synthetic seeds and survival to shoot because it is the source of energy for metabolic activity (Mallikarjuna et al., 2016).

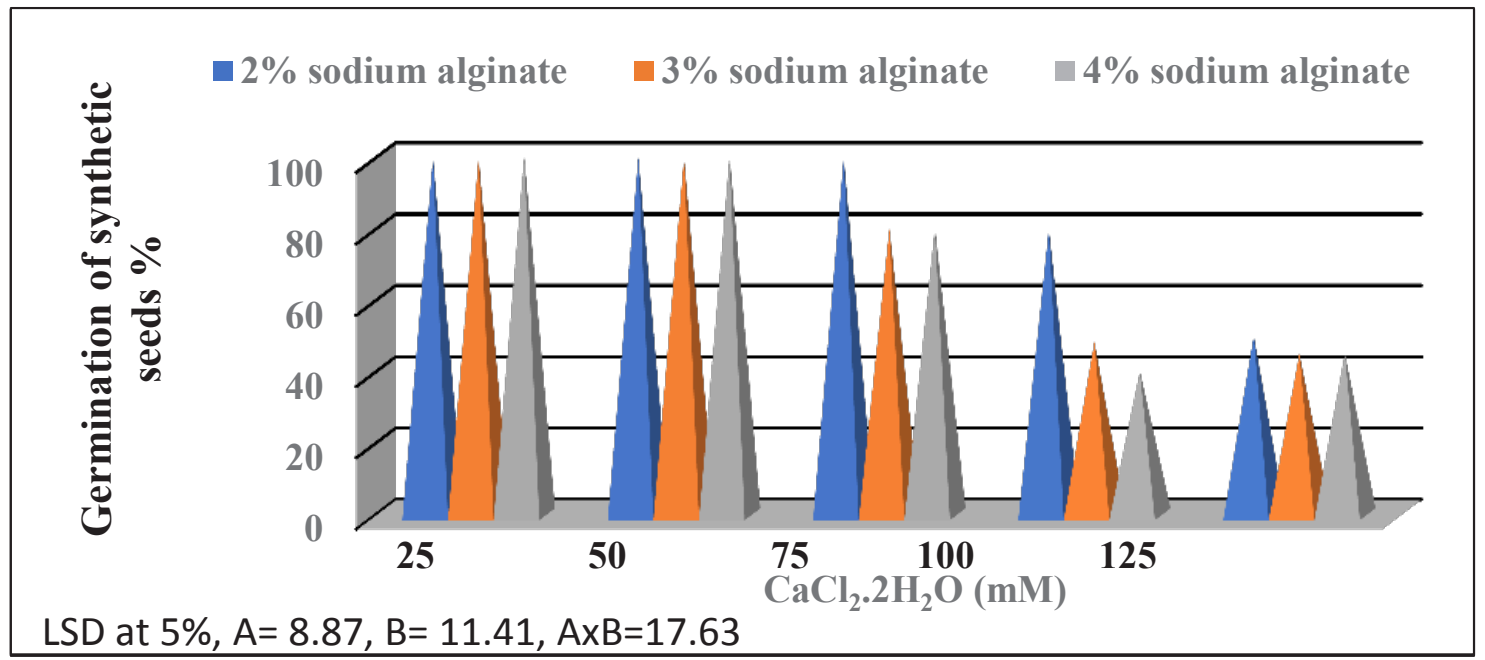

Fig. 2. Effect of different concentrations of sodium alginate and $\mathrm{CaCl}_{2} \cdot 2 \mathrm{H}_{2} \mathrm{O}$ on germination of synthetic seeds of sugarcane after four weeks.

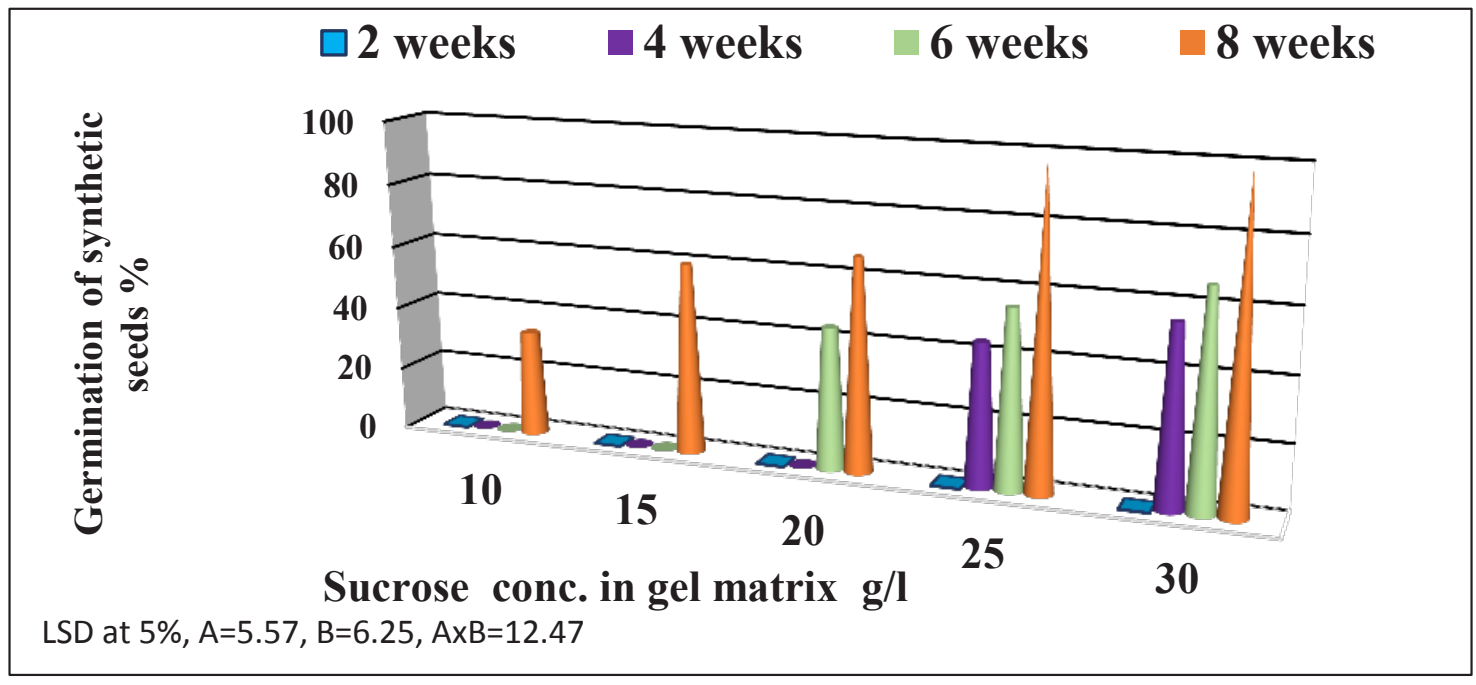

Fig. 3. Effect of different concentrations of sucrose in gel matrix on germination of synthetic seeds after different storage time from 2 to 8 weeks. 
Effect of ABA concentration in gel matrix and conservation period (week) on regrowth of synthetic seeds

Minimal growth preservation is one of the most common practices for disease-free living gene banks in terms of small areas and required labor input for sub culturing and viability testing. The reduction growth of synthetic seeds and sequential storage has been developed using both physical and chemical factors. Minimum regrowth of sugarcane synthetic seeds $(1.66 \%)$ and storage was obtained when synthetic seeds endosperm consists of MS nutrient medium supplemented with $\mathrm{ABA}$ at 0.8 or $1.00 \mathrm{mg} / \mathrm{L}$ with high viability and have the ability to regrowth when transferred to the natural conditions (Fig. 8F). Maximum synthetic seeds regrowth $(82.21 \%)$ was achieved on synthetic endosperm consists of MS nutrient medium, after storage period for 12 weeks' intervals compared with other treatments (Fig.4). It was noticed that, increasing storage time of synthetic seeds from 2 to 10 weeks gradually increased the regrowth of synthetic seeds. BadrElden (2013) showed that the storage medium supplemented with CCC, at all concentrations, the encapsulated buds of Achemia fasciata were still without regrowth after 2, 4 or 6 weeks. The growth of capsules of Stevia rebaudiana Bertoni dependent on mineral concentration and time of storage (Nower, 2014).

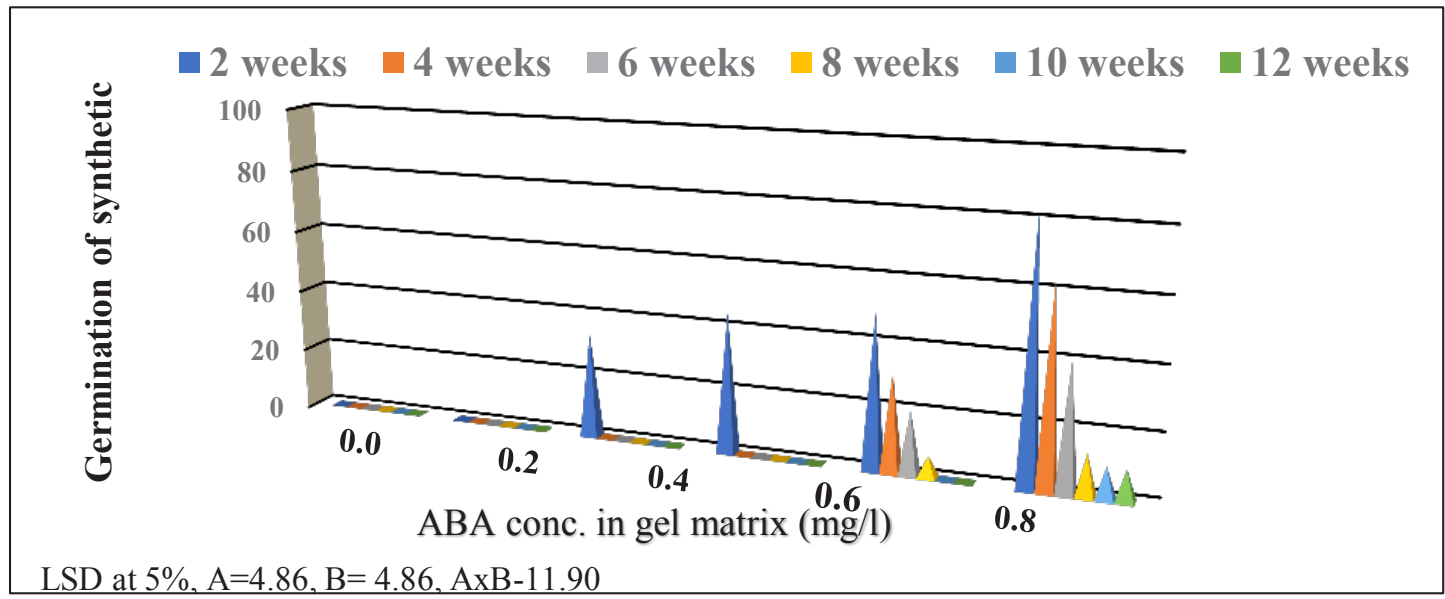

Fig. 4. Effect of ABA concentrations in gel matrix and storage time (week) on germination of synthetic seeds.

Effect of different temperatures on germination of synthetic seeds after different storage time

Encapsulated buds that were stored for different storage times at 4,10 or $15^{\circ} \mathrm{C}$ were affected by increasing or decreasing of temperature. Storage beads at $4{ }^{\circ} \mathrm{C}$ resulted in a decrease in the germination rate (Fig. $8 \mathrm{E}$ ). The cool temperature may be one reason for this, the lack of the supplemented nutrients during storage could be another. When sugarcane synthetic seeds were stored at $15^{\circ} \mathrm{C}$ for 10 or 12 weeks all beads survived in regrowth (Fig.5). Encapsulated buds when incubation at $4{ }^{\circ} \mathrm{C}$ retained viable up to 12 months and have the ability to regrowth back onto fresh medium and normal conditions. The interaction between storage time and the temperature was clear in the germination of synthetic seeds. It was observed that decline in the micro shoots to regrowth from encapsulated, which were stored at $4^{\circ} \mathrm{C}$, may be due to the limited respiration through alginate bead of encapsulated micro shoots. A similar observation was made for
Clitoria ternatea synthetic seeds which could be stored at $2{ }^{\circ} \mathrm{C}$ for 30 days without the reduction in viability, whereas control embryos obtained $4 \%$ viability after storage at cool conditions (Lisek \& Orlikowska, 2004 and Mallikarjuna et al., 2016) in Glochidion velutinum.

Effect of sugarcane bagasse and perlite for low coast production on germination of synthetic seeds

The lowest cost and the best quality of synthetic seeds were obtained when synthetic seeds were grown on the sugarcane bagasse and perlite compared to those grown on agar-gelled medium. Quality and performance of synthetic seeds grown on sugarcane bagasse or perlite were better than those on agar-gelled medium. Minimum germination of synthetic seeds in agar medium may due to an oxygen concentration in the agargelled medium is very low. These results are in agreement with Jackson (2003) who reported the effect of static liquid media, gelling agents, large 
tissue mass and warm temperatures as imposing severe limits on diffusive flux for gases such as $\mathrm{O}_{2}$, $\mathrm{CO}_{2}$ and ethylene. The germination of synthetic seeds after 10 weeks was $41.33 \%$ in MS medium contained perlite as a supporter of synthetic seeds and low cost followed by $48.00 \%$ in the sugarcane bagasse support, it may be related to the physical properties of the sugarcane bagasse (Fig. 6). Increasing of storage time of synthetic seeds from 2 weeks to 10 weeks gradually increased regrowth of synthetic seeds (Fig. 6). The maximum conversion rate of synthetic seeds was achieved on sugarcane bagasse MS medium after ten weeks of storage compared with other treatments as shown in Fig. 7. Meanwhile, MS contained sugarcane bagasse gave the highest germination rate of synthetic seeds and low cost compared with those grown in agar-gelled medium. These results are in agreement with Mohan et al. (2005), who reported that using sugarcane bagasse as a natural support were developed with low cost on strawberry. Using sugarcane bagasse as a natural support in MS rooting medium resulted in development of strawberry with low cost compared with those grown on agar media (Badr-Elden, 2012).

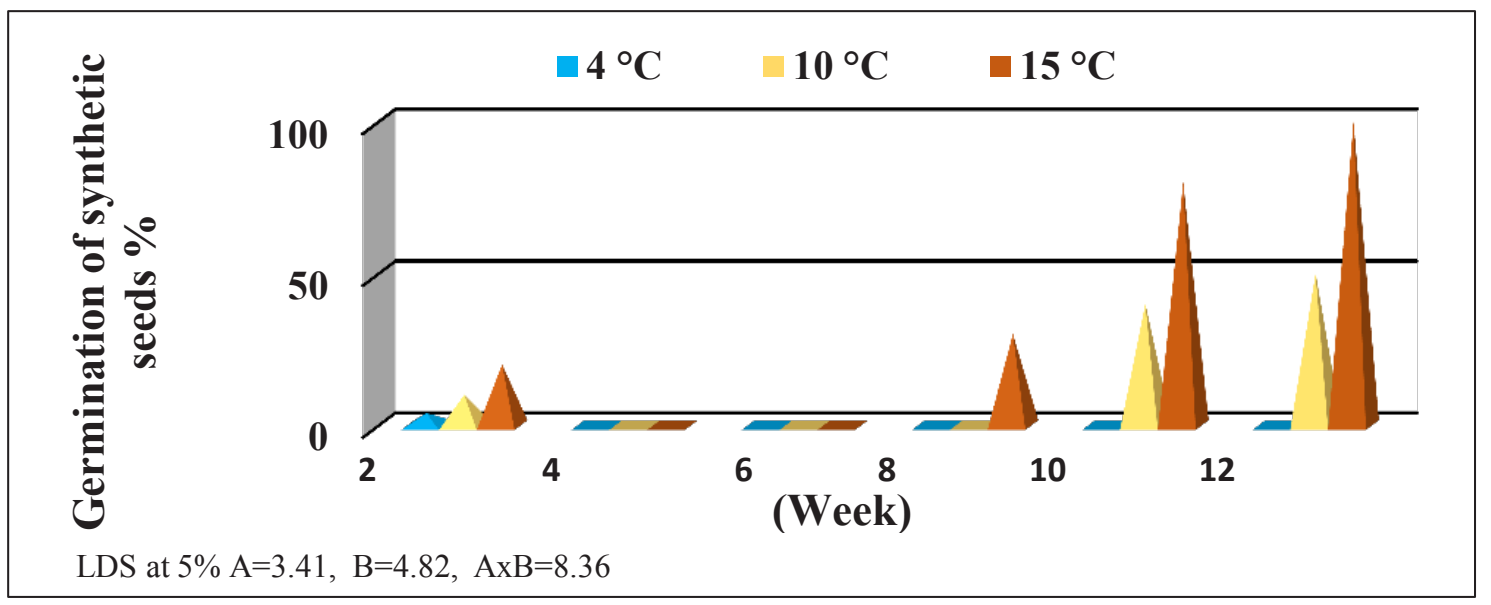

Fig. 5. Effect of different temperatures and times of storage on germination of synthetic seeds of sugarcane.

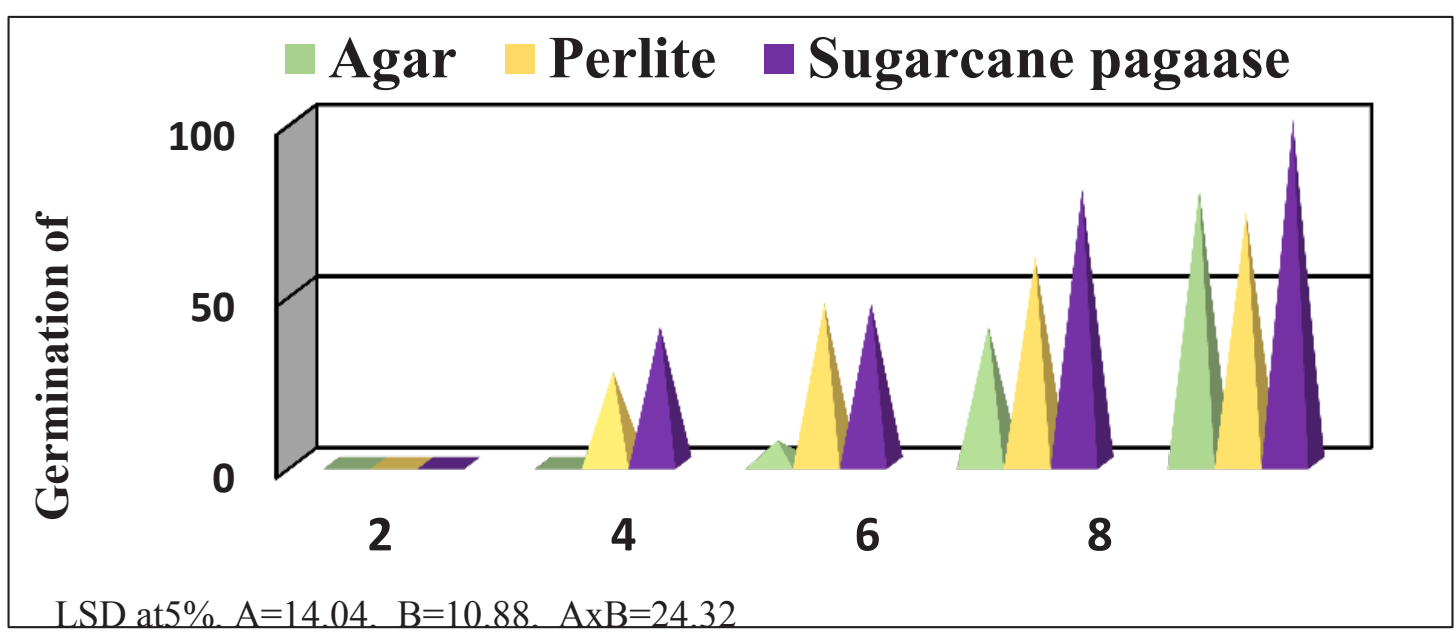

Fig. 6. Effect of sugarcane bagasse on a good-quality and low cost of synthetic seeds after different storage times. 


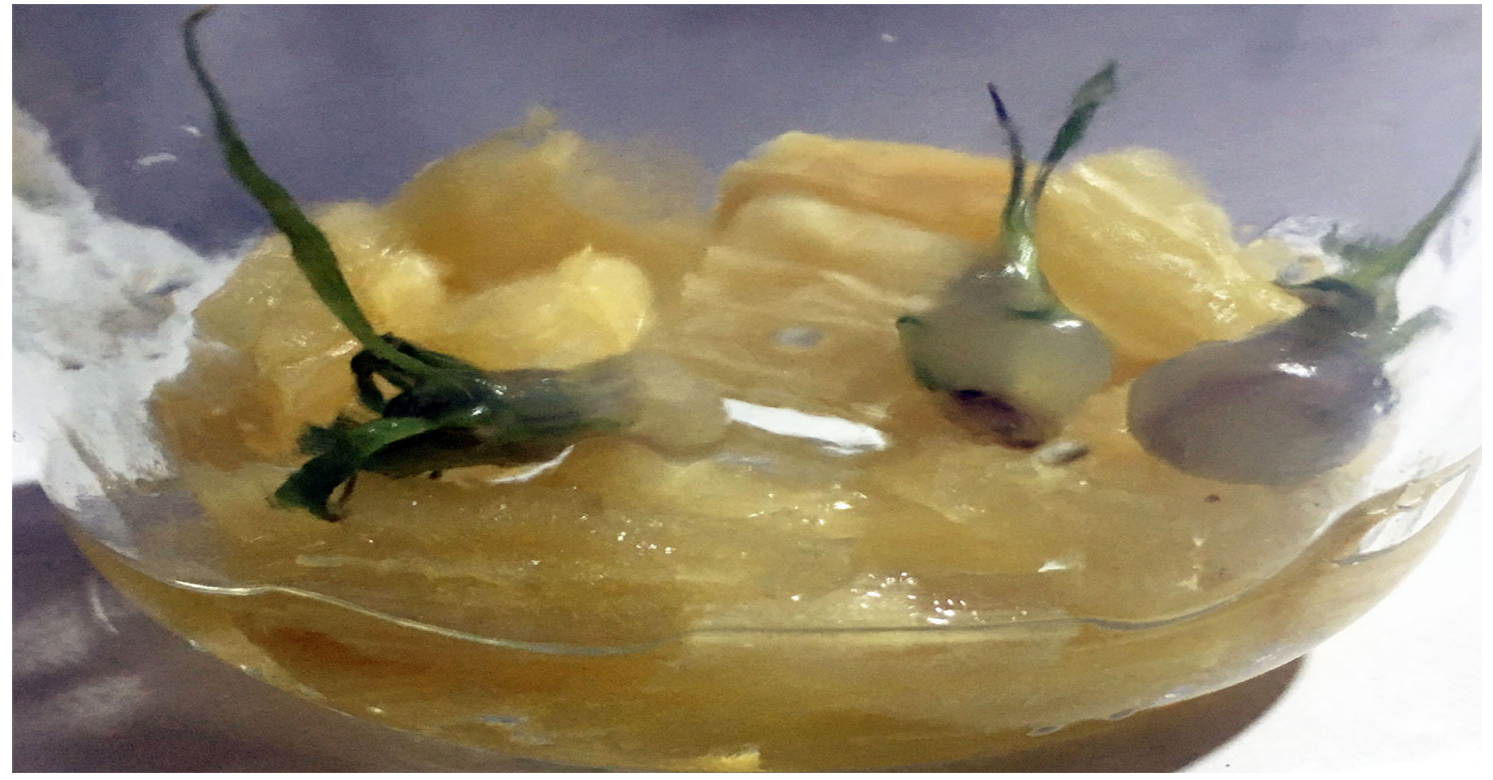

Fig. 7. Development and germination of synthetic seeds on MS medium contained $0.25 \mathrm{mg} / \mathrm{L} \mathrm{BA}$ and supported with sugarcane bagasse as a low cost of synthetic seeds storage.

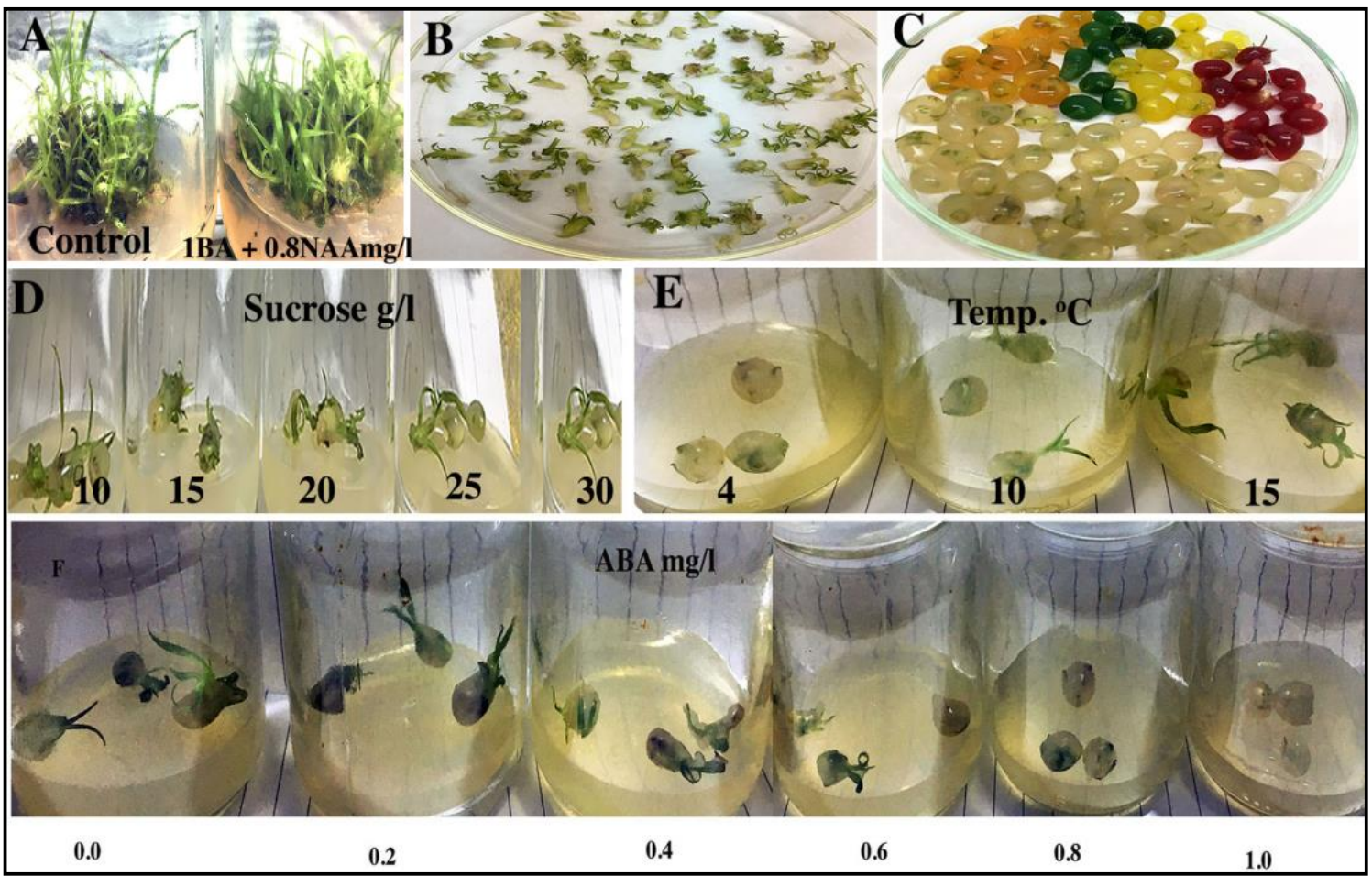

Fig. 8. A: Shoots proliferation on MS medium contained $1 \mathrm{mg} / \mathrm{L} \mathrm{BA}$ and $0.8 \mathrm{mg} / \mathrm{L}$ NAA. B: Isolated micro-shoots. C: Encapsulated of micro-shoots in $4 \%$ sodium alginate and $100 \mathrm{mM} \mathrm{CaCl} \mathbf{~}_{2} \cdot 2 \mathrm{H}_{2} \mathrm{O}$. D: Additive different concentration of sucrose to gel matrix of synthetic seeds. E: Storage of synthetic seeds at a different temperature. F: Additive different concentration of ABA in the gel matrix of synthetic seeds (in vitro storage). 


\section{Conclusion}

The main objective of this study was to use synthetic seeds of sugarcane as an important tool for propagation and germplasm conversion of this important economic plant. At proliferation stage from the results, BAalone has low effect for in vitro proliferation. On the other hand, the combined treatment of BA with NAA or IBA was important for the formation of sugarcane shoots. Formation of the synthetic seeds with synthetic endosperm consists of sodium alginate at $4 \%$, MS nutrient medium and the presence of such components like sucrose or ABA in the gel matrix ensured viability and a high frequency of shoot emergence from synthetic seeds after storage time. Further work should improve the frequency of shoots that emerge from encapsulated micro- shoots, especially from those stored long-term. However, MS medium contained sugarcane bagasse and perlite as supporter for synthetic seeds, gave the highest germination $\%$ of synthetic seeds and low cost production than those germinated on conventional agar.

\section{$\underline{\text { References }}$}

Ali, A., Gull, I., Majid, A., Saleem, A., Naz, S. and. Naveed, N.H. (2012) In vitro conservation and production of vigorous and desiccate tolerant synthetic seeds in Stevia rebaudiana. J Med. Plant Res. 6(7), 1327-1333.

Ara, H., Jaiswal, U. and Jaiswal, V.S. (2000) Synthetic seed: prospects and limitations. Curr. Sci. 78, 14381444.

Badr-Elden, A.M. (2012) An effective protocol for in vitro storage and ex vitro re-growth of strawberry capsules. Atlas J. Chem. Bioch. 1(2), 30-38.

Badr-Elden, A.M (2013) In vitro storage of synthetic seeds of Aechmea fasciata, Egypt. J. Genet. Cytol. 42, 301-317.

Belay, T., Mulugeta, D. and Derbew, B. (2014) Effects of 6- Benzyl amino purine Kinetin on in vitro shoot multiplication of sugarcane (Saccharum officinarum L.) varieties. Advances in Crop Sci. Tech. 2, 129.

Cox, M., Hogarth, M. and Smith, G. (2000) Cane breeding and improvement. In: "Manual of Cane Growing" M. H. and P. Allsopp (Ed.), pp. 91108. Indooroopilly, Australia: Bureau of Sugar Experimental Stations.

Daud, N., Taha, R.M. and. Hasbullah, N.A. (2008) Artificial seed production from encapsulated micro shoots of Saintpaulia ionantha Wendl. (African violet). J. Appl. Sci. 8(24), 4662-4667.

Grzegorczyk, I. and Wysokińska, H. (2011) A protocol for synthetic seeds from Salvia officinalis L. shoot tips. Acta Biologica Cracoviensia. Series Bota. 53(1), 80-85.

Hailu, M. (2017) In vitro propagation of selected sugarcane (Saccharum officinarum L.) varieties (C 86-56 and C 90-501) through apical meristem. Advances in Crop Sci. Tech. 5(3), 1-8.

Helal, N.A.S. (2011) The green revolution via synthetic (artificial) seeds: A Review. Res. J. Agri. Biol. Sci. 7(6), 464-477.

Jackson, M.B. (2003) Aeration stress in plant tissue cultures. Bulg. J. Plant Physiol., Special, 96-109.

Jackson, P.A. (2005) Breeding for improved sugar content in sugarcane. Field Crop Res. 92, 277-290.

Kadam, U.S., Ghosh, S.B., Strayo De, P. Suprasanna, Devasagayam, T.P.A. and Bapat, V.A. (2008) Antioxidant activity in sugarcane juice and its protective role against radiation induced DNA damage. Food Che. 106, 1154-1160.

Kaur, R. and Kapoor, M. (2017) In vitro direct plant regeneration using shoot tip explants in sugarcane (Saccharum officinarum L.) for rapid mass cloning. Agric. Sci. Digest. 37(2), 94-99.

Lakshmanan, P., Geijskes, R.J., Wang, L., Elliott, A., Grof, C.P.L., Berding, N. and Smith, G.R. (2006) Developmental and hormonal regulation of direct shoot organogenesis and somatic embryogenesis in sugarcane (Saccharum spp. interspecific hybrids) leaf culture. Plant Cell Rep. 25(10), 1007-1015.

Lisek, A. and Orlikowska, T. (2004) In vitro storage of strawberry and raspberry in calcium-alginate beads at $4^{\circ} \mathrm{C}$. Plant Cell, Tissue and Org. Cult. 78, 167172.

Mallikarjuna, B., Usha Nagalakshmi, R. and Rama Gopal, G. (2016) Providing an artificial endosperm for the effective conservation and exchange of the genetic material of Glochidion velutinum Wt., an important Ethno-medicinal plant. Int. J. Clin. Biol. Sci. 1(1), 53-62.

Mohan, R., Soccol, C.R., Quoirin, M. and Pandey, A. (2004) Use of sugarcane bagasse as an alternative low cost support material during the rooting stage of apple micropropagation. In vitro- Plant J. the Soci. for in vitro Biol.. New Mexico State University. 
Mohan, R, Chui, E.A.L. Biasi, A. and Soccol, C.R. (2005) Alternative in vitro propagation: Use of sugarcane bagasse as a low-cost support material during rooting stage of strawberry $\mathrm{Cv}$. Dover. Brazilian Archives of Biology and Tech.48, 37-4.

Murashige, T. and Skoog, F. (1962) A revised medium for rapid growth and bioassays with tobacco cultures. Physiol. Plant, 15, 473-497.

Nor Asmah, H., Nor Hasnida, H., Noraliza, A., Nashatul Zaimah, N.A. and Nadiah Salmi, N. (2012) In vitro propagation of Acacia hybrid through alginateencapsulated shoots and axillary buds. African $J$. Biotec, 11(65), 12814-12817.

Nower, A.A. (2014) In vitro propagation and synthetic seeds production: An efficient methods for Stevia rebaudiana Bertoni. Sugar Tech. 19(1), 100-108.

Nyende, A.B., Schittenhelm, S., Wagner, G.M. and Greef, J.M. (2003) Production, storability, and regeneration of shoot tips of potato (Solanum tuberosum L.) encapsulated in calcium alginate hollow beads. In Vitro Cell Dev. Biol. Plant, 39, 540-544.

Rai, M.K., Jaiswal, V.S. and Jaiswal, U. (2008) Encapsulation of shoot tips of guava (Psidium guajava L.) for short-term storage and germplasm exchange. Scientia Hort. 118, 33-38.
M.I. and Esmail, M.N.M. (2012) Development of artificial seed technology and preservation in sugar beet. Sugar Tech. 14(3), 312-320.

Snedecor, G.W. and Cochran, G.W. (1989) "Statistical Methods". $8^{\text {th }}$ ed. Ames: Iowa State Univ. Press, Iowa; USA.

Soni, V. and Sharma, P. (2017) Encapsulation of protocorm like bodies and in vitro regeneration of Asparagus racemosus willd. Biotechnol Res. 3 (4),77-79.

Soodi, N., Gupta, P.K., Srivastava, R.K. and Gosal, S.S. (2006) Comparative studies on field performance of micro propagated and conventionally propagated sugarcane plants. Plant Tissue Culture Biotech. 16, 25-29.

Tabassum, B., Nasir, I.A., Farooq, A.M., Rehman, Z. Latif, Z. and Husnain, T. (2010) Viability assessment of In vitro produced synthetic seeds of cucumber. African J. Biotech. 9(42), 7026-7032.

Tarique, H.M., Mannan, M.A., Bhuiyan, M.S.R. and Rahaman M.M. (2010) Micropropagation of sugarcane through leaf sheath culture. Int. J. Sustain. Crop Prod. 5(2), 13-15.

(Received $1 / 10$ /2017; accepted $14 / 11 / 2017$

Rizkalla, A.A., Badr-Elden, A.M., Ottai, M.E., Nasr,

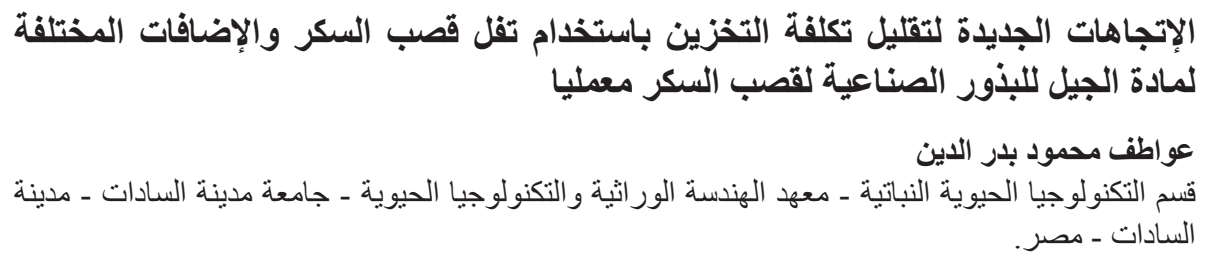

قصب السكر محصول نقدي هام في العالم، و هو المصدر الرئيسي للسكر وهو نبات معمر احادي الفلقة. وهذا

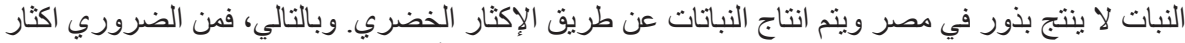

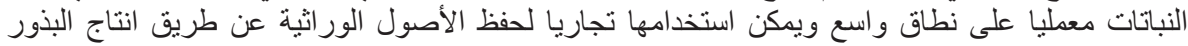

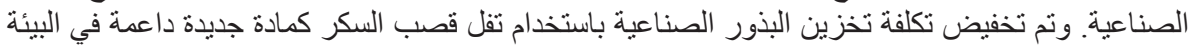

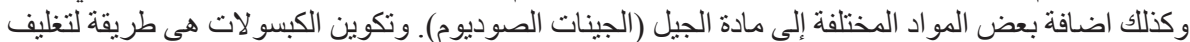

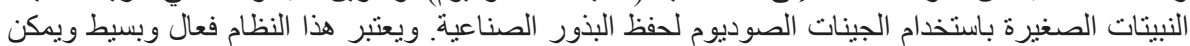

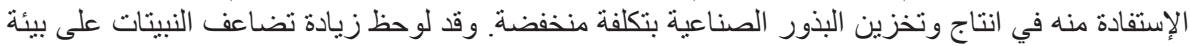

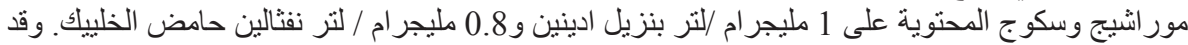

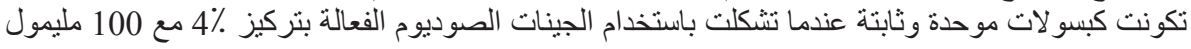

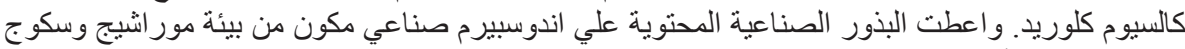

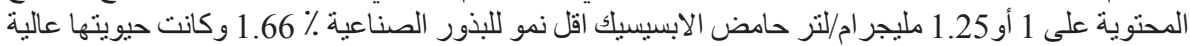

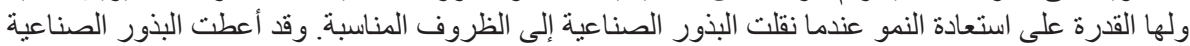

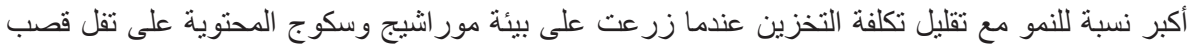

$$
\text { السكر مقارنة بالتي نمت على بيئة الاجار . }
$$

Egypt. J. Bot. Vol. 58, No.1 (2018) 